\title{
RESEARCH
}

Open Access

\section{TSG-6 secreted by human adipose tissue-derived mesenchymal stem cells ameliorates severe acute pancreatitis via ER stress downregulation in mice}

Qiang Li', Woo-Jin Song ${ }^{1}$, Min-Ok Ryu ${ }^{1}$, Aryung Nam¹, Ju-Hyun An¹, Jin-Ok Ahn ${ }^{1}$, Dong Ha Bhang ${ }^{2,3}$, Yun Chan Jung ${ }^{4}$ and Hwa-Young Youn ${ }^{1 *}$ (i)

\begin{abstract}
Background: Through recent studies, the onset of acute pancreatitis in pancreatic acinar cells (PACs) and the regulatory role of PACS in severe acute pancreatitis (SAP) have been revealed. During the early stages of pancreatitis, the endoplasmic reticulum (ER) in PACs undergoes significant changes, including swelling and vacuolization. In response to an increase in the extracellular stress in ER, PACs lose their functions, leading to cell apoptosis and inflammation response. The beneficial effects of human adipose tissue-derived mesenchymal stem cells (hAT-MSCS) on SAP have been well documented in previous studies. However, the underlying mechanism of their action remains controversial.

Methods: In this study, the therapeutic effects of intraperitoneally administered hAT-MSCs in a caerulein $(50 \mathrm{\mu g} / \mathrm{kg})$ - and lipopolysaccharide (LPS) (10 mg/kg)-co-induced SAP mouse model were evaluated. Inflammatory response and ER stress were measured in pancreatic tissue samples, and the beneficial effects were evaluated through quantitative reverse transcription polymerase chain reaction (qRT-PCR), western blot, and immunofluorescence analysis.

Results: Inflammatory response and ER stress were ameliorated following hAT-MSC injection, and the beneficial effects were observed in the absence of significant engraftment of hAT-MSCs. hAT-MSCs transfected with siRNA-targeting tumour necrosis factor-a-induced gene/protein 6 (TSG-6) were unable to inhibit ER stress and inflammation. In addition, TSG-6 from hAT-MSCs significantly suppressed ER stress-induced apoptosis and nuclear factor kappa $\mathrm{B}$ (NF-kB) activity in SAP model mice.
\end{abstract}

Conclusions: TSG-6 secreted by hAT-MSCs protects PACs in SAP model mice via the inhibition of ER stress, as well as inflammatory responses. This study has revealed a new area for ER stress-targeted therapy in SAP patients.

Keywords: Mesenchymal stem cells, Endoplasmic reticulum stress, NF-kB, TSG-6, Severe acute pancreatitis

\footnotetext{
* Correspondence: hyyoun@snu.ac.kr

'Laboratory of Veterinary Internal Medicine, College of Veterinary Medicine, Seoul National University, 1 Gwanak-ro, Gwanak-gu, Seoul 08826, Republic of Korea

Full list of author information is available at the end of the article
}

(c) The Author(s). 2018 Open Access This article is distributed under the terms of the Creative Commons Attribution 4.0 International License (http://creativecommons.org/licenses/by/4.0/), which permits unrestricted use, distribution, and reproduction in any medium, provided you give appropriate credit to the original author(s) and the source, provide a link to the Creative Commons license, and indicate if changes were made. The Creative Commons Public Domain Dedication waiver (http://creativecommons.org/publicdomain/zero/1.0/) applies to the data made available in this article, unless otherwise stated. 


\section{Background}

An increasing trend in the incidence of severe acute pancreatitis (SAP), an inflammatory disease known to cause a mortality rate as high as $43 \%$, has been observed within the past decade [1]. The histopathological mechanism underlying SAP is not yet clear, and there is no specific or effective treatment for the disease [2]. Recent studies have revealed that the initiating events of SAP, including zymogen activation and cell death, occur in pancreatic acinar cells (PACs) [3]. Furthermore, the earliest immune response in acute pancreatitis was shown to originate within the PACs that activate circulating immune cells to induce a systemic inflammatory response [4].

The endoplasmic reticulum (ER) is the most important organelle in PACs; it is involved in the synthesis, folding, and maturation of secreted and transmembrane proteins [5]. ER stress response is a common cellular process; however, overactivation of ER stress may damage the cells through ER stress-induced apoptosis [6]. ER stress is caused by a variety of conditions, including calcium ion imbalance, oxidative stress, and inflammatory responses. Pro-inflammatory cytokine-induced ER stress may act as a critical factor during the early stages of SAP, and tumour necrosis factor alpha (TNF- $\alpha$ ) is the most important pro-inflammatory cytokine that plays a central role in ER stress [7-9]. A high level of ER stress may result in the exacerbation of the inflammatory response in acute pancreatitis $[10,11]$.

Recent studies have demonstrated that mesenchymal stem cells (MSCs) ameliorate inflammatory diseases such as peritonitis, inflammatory bowel disease (IBD), diabetes, and pancreatitis [12-15]. The beneficial action of MSCs is associated with their homing effects and ability to repair tissues. Moreover, several studies have shown that MSCs may exert their effects without accumulating at the site of inflammation or tissue injury, suggestive of their actions through paracrine secretions. Furthermore, TNF- $\alpha$-induced gene/protein 6 (TSG-6) has been shown to be the key secreted mediator of the anti-inflammatory response of MSCs in peritonitis, myocardial infarction, IBD, skin wound healing, and lung injury [16-20].

In this study, we investigated the effect of human adipose tissue-derived mesenchymal stem cells (hAT-MSCs) on caerulein- and lipopolysaccharide (LPS)-co-induced SAP mouse model. We specifically focused on ER stress-induced PACs after the administration of hATMSCs. As a result, we identified a systemic secretion of TSG-6 by hAT-MSCs to regulate ER stress and nuclear factor kappa $\mathrm{B}(\mathrm{NF}-\mathrm{kB})$ signalling pathways.

\section{Methods}

\section{Cell preparation}

We obtained hAT-MSCs by the liposuction of the abdominal subcutaneous fat from a healthy donor after receiving written informed consent and according to the guidelines of the Institutional Review Board (IRB) of the $\mathrm{R}$ bio (IRB No. RBIO-2016-04-001). The cells were isolated and characterised as described in the Additional file 1: Methods, and the expression of stem cell markers was determined by flow cytometry (Additional file 2: Figure S1A). In addition, their differentiation abilities were confirmed through three-lineage stem cell differentiation kits (Invitrogen, Carlsbad, CA, USA), according to the manufacturer's instructions (Additional file 2: Figure S1B). hAT-MSCs at passages 3-5 were used in the following experiments.

We separated PACs from C57BL/6 mice using collagenase digestion, as previously described $[21,22]$. Upon the complete dissociation of the pancreatic tissue, the enzymatic reaction was stopped with the addition of cold HBSS (Invitrogen) supplemented with 5\% foetal bovine serum (FBS; PAN Biotech, Aidenbach, Germany). The cell pellet was resuspended in modified PAC maintenance medium containing Dulbecco's modified Eagle's medium (DMEM)/ F-12 (Invitrogen), 10\% FBS (PAN Biotech), 1\% penicillinstreptomycin (PAN Biotech), $0.25 \mathrm{mg} / \mathrm{mL}$ of soybean trypsin inhibitor (Sigma-Aldrich, St. Louis, MO, USA), and $10 \mathrm{ng} / \mathrm{mL}$ of recombinant human epidermal growth factor (Invitrogen), and incubated at $37{ }^{\circ} \mathrm{C}$ in a humidified atmosphere with $5 \% \mathrm{CO}_{2}$ [23]. The isolated PACs were cultured for $24 \mathrm{~h}$ and characterised (Additional file 3: Figure S2A-C). Additionally, the viability of LPS- and caerulein-co-induced primary PACs were assessed using the D-plus ${ }^{\text {tm }}$ CCK kit (Dongyinbio, Seoul, Korea) at different time points, according to the manufacturer's instructions (Additional file 3: Figure S2D).

\section{Animals}

Male C57BL/6 mice weighing approximately 20-25 g were purchased from the Central Lab Animal Inc. (Seoul, Korea). All mice were housed in a specific pathogen-free standard room under controlled conditions of temperature $\left(20-22{ }^{\circ} \mathrm{C}\right)$, humidity $(50 \% \pm 5 \%)$, and light cycle (12:12 h light-dark). The study and all experimental procedures involving animals were approved by the institutional Animal Care and Use Committee of Seoul National University (SNU-180410-4), and the experiments were performed as per the Guidelines for animal experiments. Experimental mice were fasted for $12 \mathrm{~h}$ before treatment; they had free access to water.

\section{Transfection of hAT-MSCs with TSG- 6 siRNA}

hAT-MSCs were plated in six-well plates and 40-50\% confluent cells were transfected with TSG-6 siRNA (sc-3981; Santa Cruz Biotechnology, Dallas, TX, USA) or scrambled (scr) siRNA (sc-37007; Santa Cruz Biotechnology) for $48 \mathrm{~h}$ using Lipofectamine RNAiMAX (Invitrogen), according to the manufacturer's instructions. 
TSG-6 knockdown in these cells was confirmed using quantitative reverse transcription polymerase chain reaction (qRT-PCR) before their application for further studies.

\section{Induction and treatment of SAP}

For the induction of the SAP model, mice were administered with an hourly intraperitoneal injection of caerulein $(50 \mu \mathrm{g} / \mathrm{kg}$, six times; Sigma-Aldrich) and LPS $(10 \mathrm{mg} / \mathrm{kg}$; Sigma-Aldrich), as previously described [24]. To evaluate the therapeutic efficacy, mice treated once with or without hAT-MSCs $\left(1 \times 10^{6}\right.$ cells/per mouse $)$ were sacrificed 12 , 24 , or $48 \mathrm{~h}$ after hAT-MSC infusion. Additionally, SAP mice were randomised into the phosphate-buffered saline (PBS)-treated, hAT-MSC-treated, scr siRNA-transfected hAT-MSC-treated, or TSG-6 siRNA-transfected hATMSC-treated groups ( $n=8$, in each group). The mice were administered with $200 \mu \mathrm{L}$ of PBS after LPS infusion. In each experiment, naive mice were treated with PBS alone or PBS in combination with hAT-MSCs as the sham and MSC sham groups, respectively ( $n=5$, in each group). The mice were sacrificed, and the serum and pancreatic tissues were collected for further analysis.

\section{Assessment of pancreatitis severity}

To assess the severity of pancreatitis and choose an appropriate time point for further evaluation, parameters for acute pancreatitis, including pancreatic oedema (pancreas/body weight ratio), and serum amylase and lipase activities were measured 12, 24, and $48 \mathrm{~h}$ after hAT-MSC administration. Amylase and lipase activities were evaluated using the mouse pancreatic amylase enzyme-linked immunosorbent assay (ELISA) kit (Cusabio Biotech Co, Ltd., Wuhan, China) and pancreatic lipase ELISA kit (Mybiosource, San Diego, CA, USA), respectively.

\section{Histological examination}

Pancreas and lung tissues were rinsed and fixed in 4\% paraformaldehyde, embedded in paraffin, and cut into $4-\mu \mathrm{m}$ sections that were stained with haematoxylin and eosin (H\&E). To quantify pancreatic tissue injury, 10 random fields per group were evaluated by two investigators in a blinded manner under a light microscope (magnification, $\times 200$ or $\times 400$ ) using a modified evaluation system, as described in Additional file 4: Table S1 [25]. In addition, pancreatitis-associated lung injury was evaluated as per the previous report (Additional file 5: Figure S3) [26].

\section{Co-culture of isolated PACs and hAT-MSCs}

All co-culture experiments were conducted in six-well cell culture plates containing $0.4-\mu \mathrm{m}$ pore-sized transwell inserts (SPL Life Science, Pocheon, Korea). A total of $3 \times 10^{5}$ hAT-MSCs, scr siRNA-transfected hAT-MSCs, or TSG-6 siRNA-transfected hAT-MSCs were plated at the bottom of the six-well plates (SPL Life Science). After the attachment of cells to the plates, isolated PACs were seeded onto the transwell inserts and stimulated with $100 \mathrm{nM}$ caerulein (Sigma-Aldrich) and $10 \mathrm{mg} / \mathrm{mL}$ LPS (Sigma-Aldrich) for $12 \mathrm{~h}$. The co-culture system was maintained at $37{ }^{\circ} \mathrm{C}$ in a humidified atmosphere with $5 \% \mathrm{CO}_{2}$. Naive PACs and non-hAT-MSCs treated with caerulein and LPS served as the naive and positive control groups, respectively.

\section{Quantitative reverse transcription polymerase chain reaction (qRT-PCR) analysis}

Total RNA was extracted from the homogenised pancreatic tissue, isolated PACs, and hAT-MSCs using the Easy-BLUE Total RNA Extraction kit (Intron Biotechnology, Seongnam, Korea), according to the manufacturer's instructions. cDNA was synthesised from $1 \mu \mathrm{g}$ of total RNA with CellScript All-in-One cDNA Master Mix (CellSafe, Yongin, Korea), and the samples were analysed in triplicate using AMPIGENE qPCR Green Mix Hi-ROX with the SYBR Green dye (Enzo Life Sciences, Farmingdale, NY, USA). The expressions of target genes were analysed according to the $2^{-\Delta \Delta / C t s}$ method and normalised to the mRNA levels of glyceraldehyde-3-phosphate dehydrogenase (GAPDH). The primer sequences used in this study are listed in Additional file 4: Table S2.

\section{Western blot analysis}

The total protein from pancreatic tissue and isolated PACs was extracted in PRO-PREP Protein Extraction Solution (Intron Biotechnology) on ice according to the manufacturer's instructions, and the protein concentrations were measured using the Bio-Rad DC Protein Assay Kit (Bio-Rad, Hercules, CA, USA). A total of $20 \mu \mathrm{g}$ of each of the proteins was subjected to electrophoresis on $10 \%$ sodium dodecyl sulphate-polyacrylamide gels, and the protein bands were transferred onto polyvinylidene difluoride membranes (EMD Millipore, Billerica, MA, USA). The membranes were incubated in $5 \%$ non-fat dry milk in Tris-buffered saline containing $0.1 \%$ Tween-20 for $1 \mathrm{~h}$ and treated with antibodies against anti-caspase-12 (1:500), anti-CCAAT-enhancer-binding protein homologous protein (CHOP) (1:500), anti-78-kDa glucose-regulated protein (Grp78) (1:1000) (all from Cusabio Biotech Co), anti-TNF- $\alpha$ (1:1000), anti-NF-kB-p65 (1:1000), and anti-NF-кB-p-p65 (1:1000) (Cell Signaling Technology, Beverly, Massachusetts, USA) at $4{ }^{\circ} \mathrm{C}$ overnight. The membranes were incubated with anti-rabbit or anti-mouse IgG (Santa Cruz Biotechnology) as the secondary antibodies (1:2000) for $1 \mathrm{~h}$. The protein bands were visualised using enhanced chemiluminescence (Advansta, Menlo 
Park, CA, USA) and normalised to the levels of $\beta$-actin (Santa Cruz Biotechnology).

\section{Quantification of cell apoptosis}

Cell death was analysed for PACs treated with LPS plus caerulein. Paraffin-embedded pancreatic tissue sections were deparaffinised in xylene and rehydrated with ethanol solution. Apoptosis rates were determined by TUNEL staining (Apo-BrdU DNA Fragmentation Assay Kit; BioVision, San Francisco, USA), following the manufacturer's instructions. Immunoreactive cells were counted in 10 random fields per group using an EVOS FL microscope (Life Technologies, Darmstadt, Germany).

\section{Standard curve of human GAPDH}

Standard curves were generated by adding serial dilutions of hAT-MSCs to mouse tissues, including those of the heart, liver, lung, kidney, spleen, brain, and pancreas. 100-100,000 stem cells were added to the whole mouse organs prior to homogenisation and total RNA was extracted using the Easy-BLUE Total RNA Extraction kit (Intron Biotechnology). cDNA was generated (CellScript All-in-One cDNA Master Mix, CellSafe) using $1 \mu \mathrm{g}$ of total RNA. The synthesized cDNA was analysed by qRT-PCR with human-specific GAPDH, and the final value for total CDNA in the sample was corrected by parallel qRT-PCR assays with primers that amplified both the human/mouse genes for GAPDH, as previously described [17, 27].

\section{Statistical analysis}

Data are shown as mean \pm standard deviation. Differences between groups were compared by one-way analysis of variance or Student's $t$ test with GraphPad Prism v.6.01 software (GraphPad Inc., La Jolla, CA, USA). $P<$ 0.05 was considered as statistically significant.

\section{Results}

Intraperitoneally administered hAT-MSCs ameliorated SAP To determine the effect of hAT-MSCs on SAP, we treated mice with hAT-MSCs and the treatment effects were evaluated 12, 24, and $48 \mathrm{~h}$ after hAT-MSC infusion. Histological examination of the pancreatic tissues after the induction of SAP revealed tissue injury characterised by tissue oedema, acinar cell necrosis, and inflammatory cell infiltration (Fig. 1a). In comparison with the SAP + PBS group, the SAP + MSC group showed a significant reduction in the pancreatic tissue injury at the 12,24 , and $48 \mathrm{~h}$ time points (Fig. 1b, c, d). Pancreatic oedema was evaluated based on the pancreas to body weight ratio. SAP models showed a significant increase in the pancreas to body weight ratio, while hAT-MSC treatment attenuated these effects at the 12, 24, and $48 \mathrm{~h}$ time points (Fig. 1e). The analysis of the serum pancreatic enzyme activity showed that hAT-MSC administration markedly decreased the activities of serum amylase and lipase at the $48 \mathrm{~h}$ time point (Fig. 1f, g).

\section{hAT-MSCs reduced the inflammatory response and ER stress in pancreatic tissues}

To determine whether hAT-MSCs regulate inflammatory response under conditions of inflammation, the mRNA levels of inflammatory cytokines in the pancreatic tissue were measured by qRT-PCR analysis. The expression levels of pro-inflammatory cytokines (TNF- $\alpha$, interleukin $[\mathrm{IL}]-1 \beta$, and IL-6) were markedly increased in SAP + PBS group but significant decreased in the group treated with hAT-MSCs (Fig. 2a). While the mRNA level of the anti-inflammatory cytokine IL-10 failed to increase in the SAP + PBS group, it was significantly elevated in the SAP + MSC group (Fig. 2b). In addition, we evaluated the expression levels of the relative markers of ER stress (Grp78, CHOP, and caspase-12) by qRT-PCR and western blot analyses, and found that the hAT-MSC-treated group showed a marked decrease in the mRNA levels of Grp78, CHOP, and caspase-12, compared to the case in the SAP + PBS group. Similar results were observed for protein analysis, wherein a significant decrease in ER stress-related marker levels was observed in the SAP + MSC group, compared to the case in the SAP + PBS group (Fig. 2c, d).

\section{Intraperitoneally injected hAT-MSCs did not accumulate in the pancreatic tissues}

To detect the fate of hAT-MSCs infused intraperitoneally into SAP mice, we quantified the injected hAT-MSCs $\left(1 \times 10^{6}\right.$ cells $)$ by constructing standard curves using qRT-PCR (Fig. 3a). After $2 \mathrm{~h}$ of administration, the percentages of hAT-MSCs detected in the heart, liver, lung, kidney, spleen, brain, and pancreas of SAP mice were $0.079 \%, 0.415 \%, 0.023 \%, 0.046 \%, 0.059 \%$, $0.035 \%$, and $0.001 \%$, respectively (Fig. $3 \mathrm{~b}$ ). After 12 to $24 \mathrm{~h}$, no hAT-MSCs were detected in the pancreatic tissue (Fig. 3c, d). At the $48 \mathrm{~h}$ time point, a few hAT-MSCs were observed in the spleen and brain tissues, but not in other tissues (Fig. 3e).

\section{TSG- 6 secreted by hAT-MSCs alleviated the ER stress} levels in PACs in vitro

To evaluate the effects of TSG-6 secreted by hAT-MSCs on ER stress, hAT-MSCs were transduced with TSG-6 siRNA or scr siRNA and the gene expression of TSG-6 was measured by qRT-PCR analysis. hAT-MSCs transfected with TSG-6 siRNA showed a significant decrease in the expression of the TSG- 6 mRNA level, whereas no significant change in the TSG-6 mRNA level was 
A
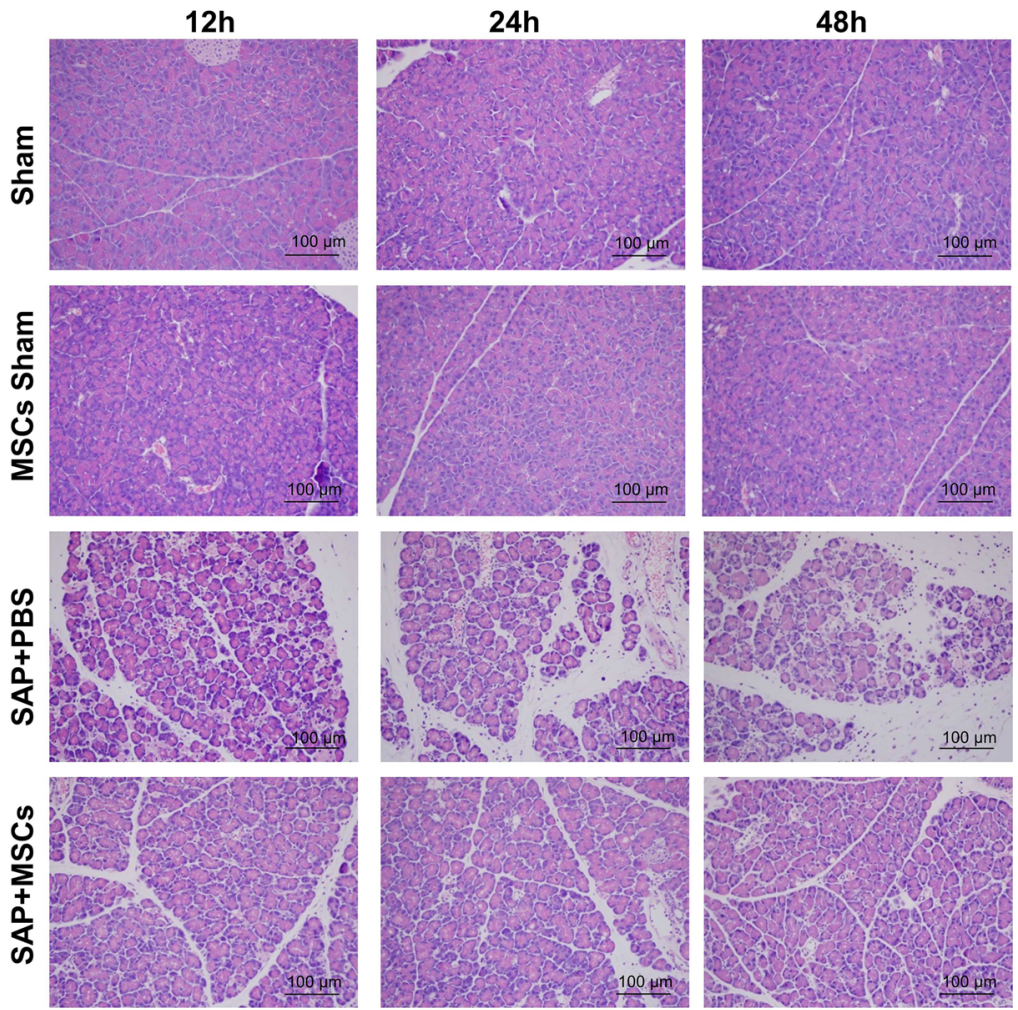

B

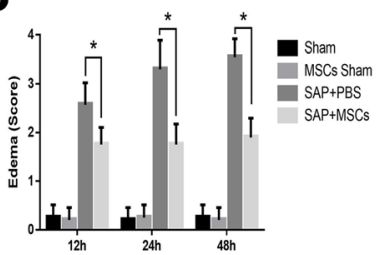

E

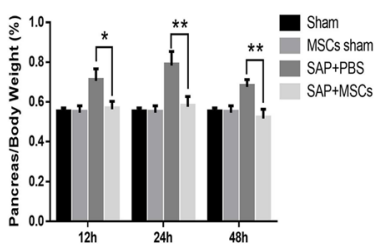

C

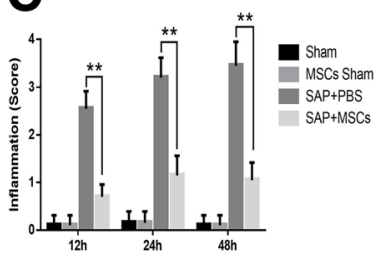

$\mathbf{F}$

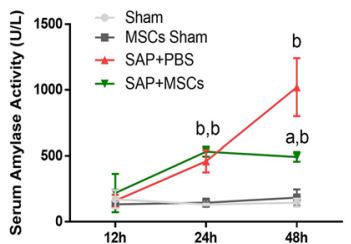

D

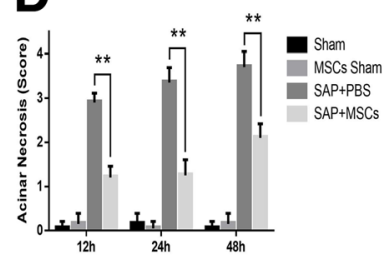

G

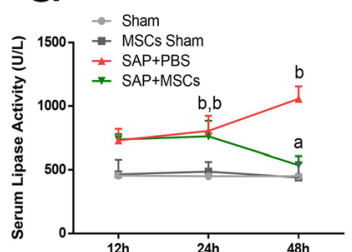

Fig. 1 Effects of intraperitoneally injected hAT-MSCs on caerulein- and LPS-co-induced severe acute pancreatitis (SAP). Mice were treated with caerulein $(50 \mu \mathrm{g} / \mathrm{kg}$, six times) and LPS (10 mg/kg) to induce SAP. Mice were sacrificed 12, 24, and $48 \mathrm{~h}$ after hAT-MSCs infusion. a Representative pathological changes in H\&E-stained pancreatic tissue sections at $\times 200$ magnification. b, c, $\mathbf{d}$ Histological analysis of the severity of acute pancreatitis. e The ratio of pancreas weight to body weight was measured. $\mathbf{f}, \mathbf{g}$ The activities of digestive enzymes such as serum amylase and lipase were measured. Each value represents the mean \pm SD. ${ }^{*} P<0.05,{ }^{* *} P<0.01,{ }^{a} P<0.01$ versus SAP + PBS group at the same time point; ${ }^{b} P<0.01$ versus MSC sham group at the same time point ( $n=5-8$ mice per group), MSC mesenchymal stem cells, PBS phosphate-buffered saline, SAP severe acute pancreatitis

observed in hAT-MSCs transfected with control siRNA (scr siRNA), compared to the case for naive hAT-MSCs (Fig. 4a).

hAT-MSCs transfected with TSG-6 siRNA showed no change in the differentiation potential in vitro (Additional file 1: Figure S1B). We co-cultured caerulein- and LPS-stimulated PACs with naive or siRNA-transfected
hAT-MSCs in a transwell system for $12 \mathrm{~h}$ and found that the expression levels of Grp78, CHOP, and caspase-12 were significantly decreased in the hAT-MSC- and scr siRNA-transfected hAT-MSC-treated groups, compared to the case for the positive control and TSG-6 siRNA-transfected hAT-MSC-treated groups (Fig. 4b). However, no significant change was observed in the 
A

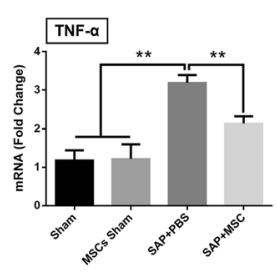

C
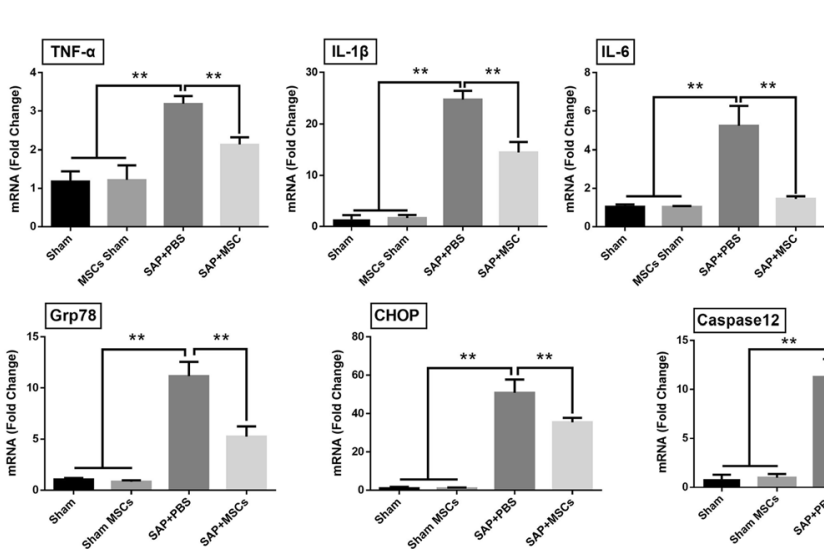

B
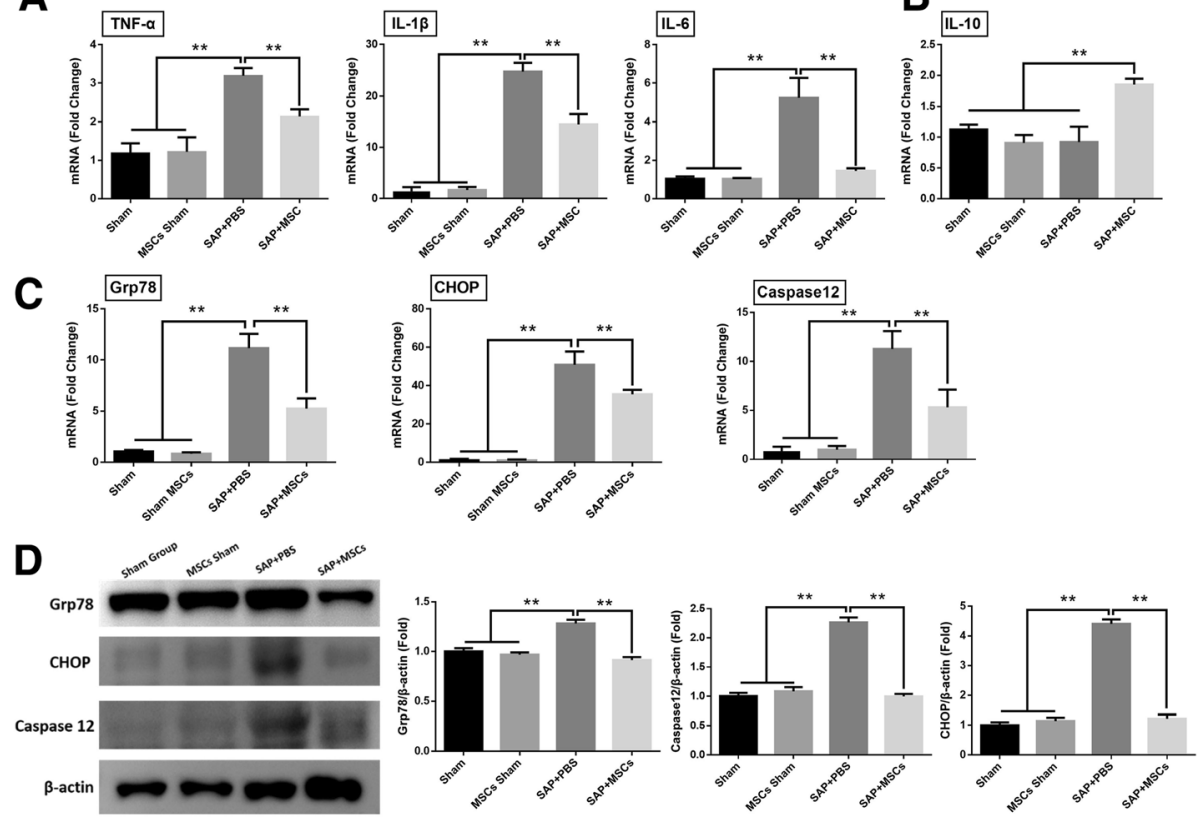

Fig. 2 Effects of hAT-MSCs on inflammatory cytokine and ER stress levels. $\mathbf{a}, \mathbf{b}$ The mRNA expression levels of inflammatory cytokines in the pancreatic tissue at the $48 \mathrm{~h}$ time point. $\mathbf{c}$ mRNA and (d) protein expression levels of Grp78, CHOP, and caspase-12 in the pancreatic tissue $48 \mathrm{~h}$ after the administration of hAT-MSCs. Results are presented as the mean \pm SD obtained from three independent experiments. ${ }^{*} P<0.05$, ${ }^{* *} P<0.01$. CHOP CCAAT-enhancer-binding protein homologous protein, Grp7 78-kDa glucose-regulated protein, IL interleukin, MSC mesenchymal stem cells, PBS phosphate-buffered saline, SAP severe acute pancreatitis, TNF-a tumour necrosis factor alpha

expression levels of ER stress markers in the group treated with TSG-6 siRNA-transfected hAT-MSCs, compared to the positive control group (Fig. 4c). NF- $\mathrm{kB}$ is related with ER stress-induced apoptosis and inflammatory response as a multi-functional transcript factor. To determine the relationship between TSG- 6 and NF- $\mathrm{KB}$ in PACs, we measured the NF- $\mathrm{kB}$ activity by evaluating the ratio of phosphorylated P56 to P56. NF-kB activity was significantly suppressed in the hAT-MSC- and scr siRNA-transfected hAT-MSC-treated groups, compared to the case in the positive control and TSG-6 siRNAtransfected hAT-MSC-treated groups (Fig. 4d).

To determine whether TSG-6 regulates PAC apoptosis, we quantified the PAC apoptotic ratio using the
A

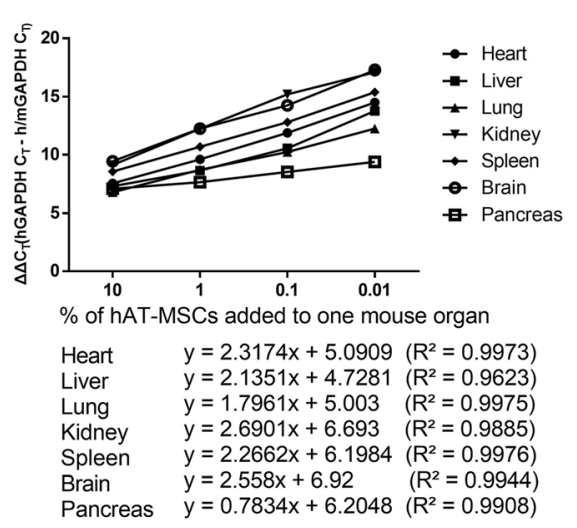

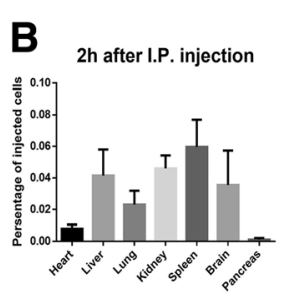

D $24 \mathrm{~h}$ after I.P. injection

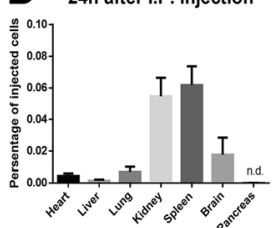

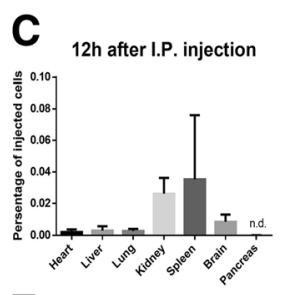

E $48 \mathrm{~h}$ after I.P. injection

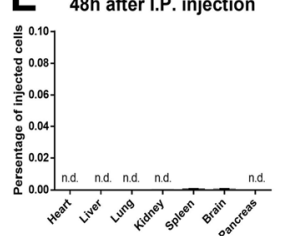

Fig. 3 Assay for evaluating the fate of intraperitoneally injected hAT-MSCs. A serial dilution of $1 \times 10^{6}$ hAT-MSCs was injected in mice to investigate the expression level of human/mouse GAPDH and human-specific GAPDH. a Standard curves for quantitative reverse transcription polymerase chain reaction assay of human-specific mRNA levels of GAPDH. b, c, d, e Distribution of hAT-MSCs in seven organs 2, 12, 24, and 48 h after their intraperitoneal infusion. The results are representative of three independent experiments. GAPDH glyceraldehyde-3-phosphate dehydrogenase, hAT-MSCs human adipose tissue-derived mesenchymal stem cells, I.P. intraperitoneal 


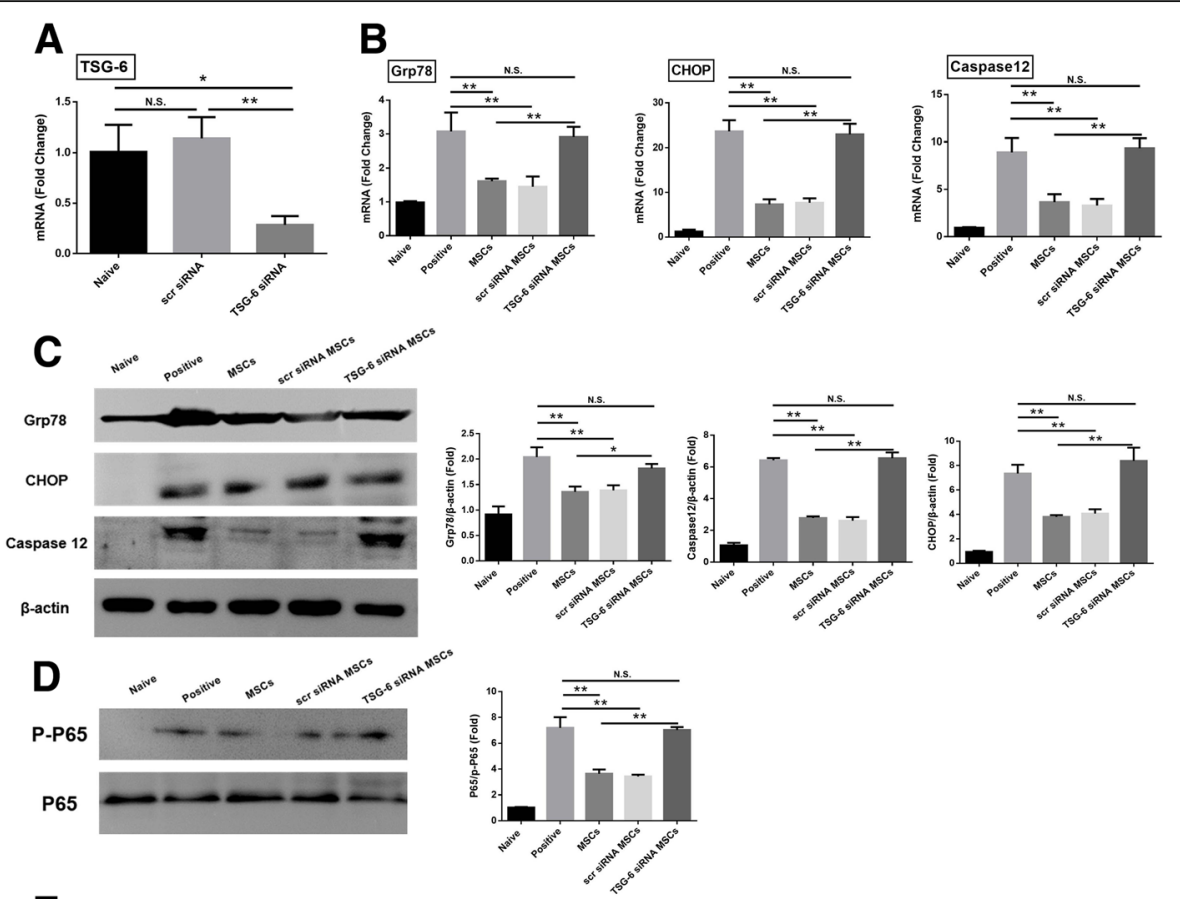

\section{E}

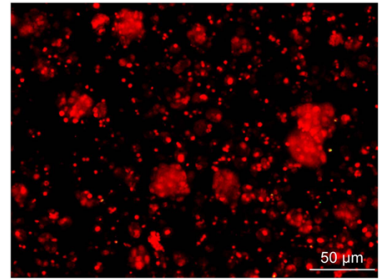

Naive

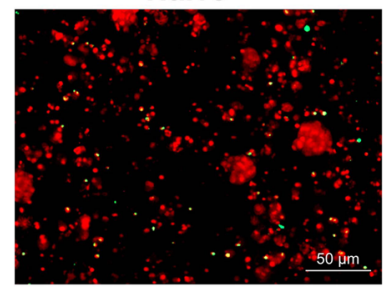

Scr SIRNA

MSCs

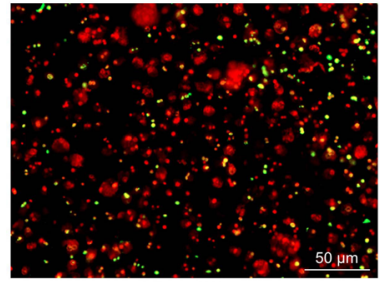

Positive

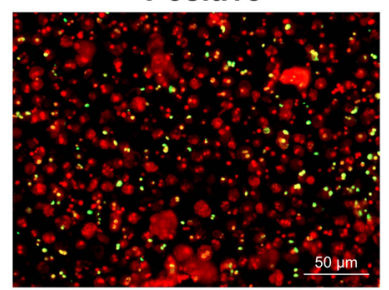

TSG-6 SIRNA MSCs

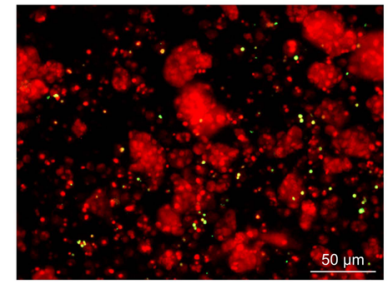

MSCs

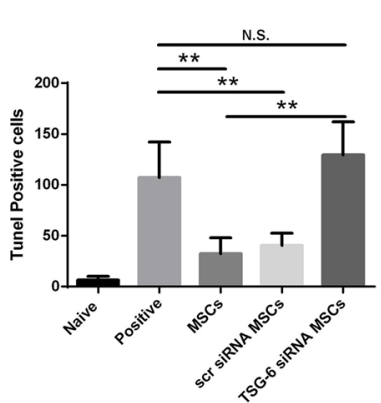

Fig. 4 In vitro effect of TSG-6 on caerulein- and LPS-stimulated primary pancreatic acinar cells (PACs). a TSG-6 mRNA expression levels in hATMSCs transfected with TSG-6 siRNA (TSG-6 siRNA MSCs), hAT-MSCs transfected with control siRNA (scr siRNA MSCs), and naive hAT-MSCs (MSCs). b, c Caerulein- and LPS-stimulated primary PACs were indirectly co-cultured with each of the three hAT-MSC types for 12 h. b Grp78, CHOP, and caspase-12 mRNA expression levels in primary PACs. c Grp78, CHOP, and caspase-12 protein expression levels. d The expression levels of NF-KB p65 activity were analysed by western blotting. e TUNEL staining in PACs in each group observed at $\times 200$ magnification. TUNEL staining revealed the number of cells undergoing apoptosis or pyroptosis. Results are presented as the mean \pm SD obtained from three independent experiments ${ }^{*} P<0.05,{ }^{* *} P<0.01$. CHOP CCAAT-enhancer-binding protein homologous protein, Grp7 78-kDa glucose-regulated protein, MSC mesenchymal stem cells, PBS phosphate-buffered saline, SAP severe acute pancreatitis, scr scrambled, TSG-6 tumour necrosis factor-a-induced gene/protein 6

TUNEL assay. The results showed that treatment with naive hAT-MSCs or hAT-MSCs transduced with scr siRNA may significantly reduce the apoptotic ratio, compared to the case in the positive control group; however, we failed to observe similar effects with hAT-MSCs transduced with TSG-6 siRNA.

\section{Knockdown of TSG-6 in hAT-MSCs failed to ameliorate} SAP

We evaluated whether hAT-MSCs transduced with TSG-6 siRNA ameliorate SAP. In comparison with the PBS-treated group, the groups treated with hAT-MSCs and scr siRNA-transfected hAT-MSCs showed a significant 
reduction in the degree of pancreatic tissue oedema, acinar cell necrosis, and inflammatory cell infiltration. We failed to observe this effect in the group treated with TSG-6 siRNA-transfected hAT-MSCs (Fig. 5a, b). TUNEL staining was performed on the pancreatic tissue sections, and the result showed that the number of TUNEL-positive cells was significantly reduced after treatment with hAT-MSCs or scr siRNA-transfected hAT-MSCs; no significant improvement in apoptosis was observed for the group treated with TSG-6 siRNA-transfected hAT-MSCs and PBS (Fig. 5c). In comparison with the PBS-treated group, the groups treated with hAT-MSCs and scr siRNA-transfected hAT-MSCs showed a significant reduction in the levels of serum amylase and lipase activities, and TNF- $\alpha$ concentration (Fig. 5d). On the contrary, no effect on SAP was seen in the group treated with TSG-6 siRNA-transfected hAT-MSCs.

We assessed the expression level of ER stress-related markers in the pancreatic tissues of SAP mice. Intraperitoneal administration of hAT-MSCs transfected with TSG-6 siRNA failed to reduce the expression levels of ER stress-related markers at both the mRNA and protein levels (Fig. 6a, b). We investigated the protein levels of p65 and phosphorylated p65 in the pancreatic tissue by western blot analysis, to evaluate whether TSG-6 could modulate NF- $\mathrm{KB}$ signalling in vivo. In addition, we measured local TNF- $\alpha$ protein expression levels in the pancreatic tissues (Fig. 6c). As a result, we found that the

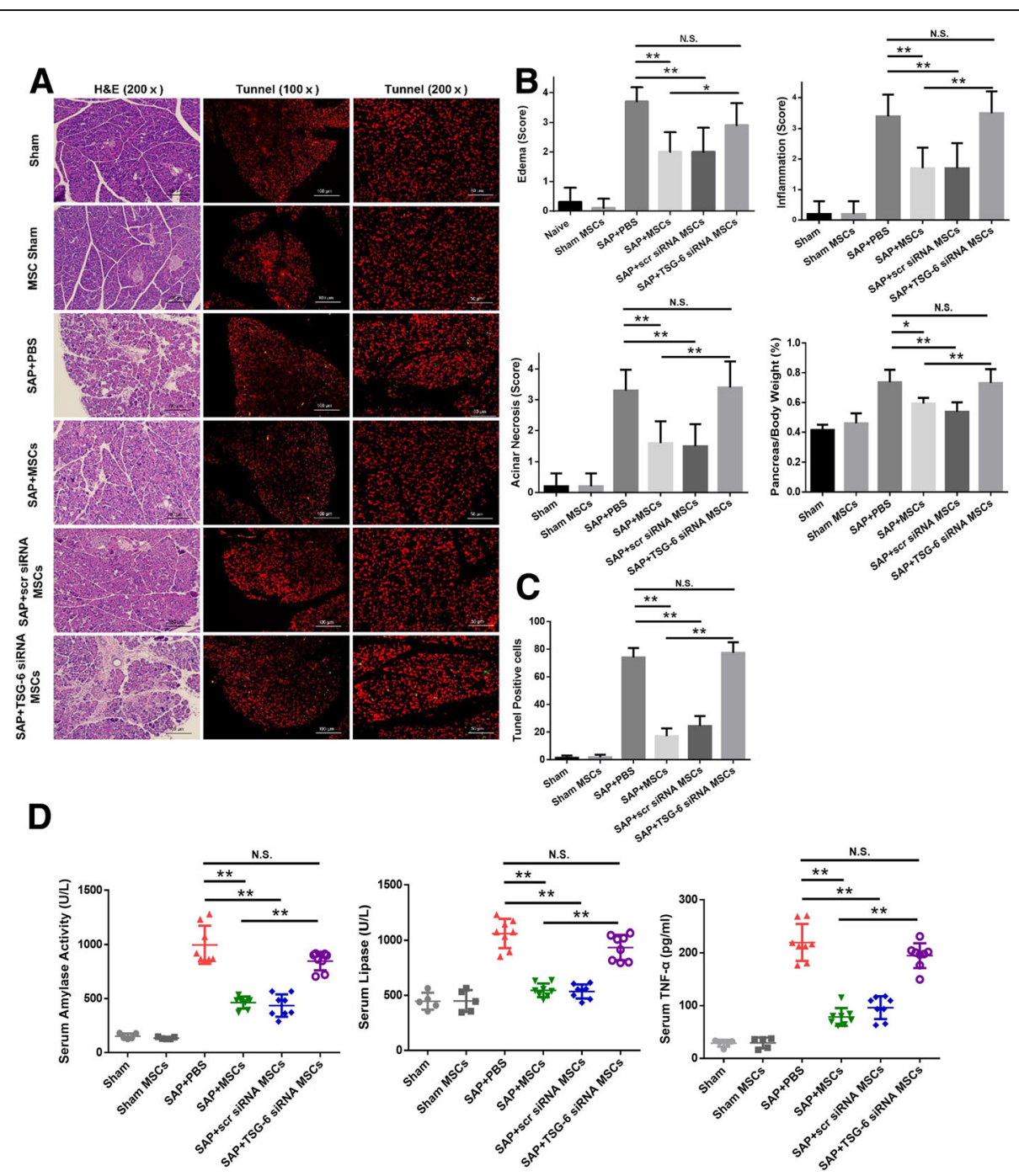

Fig. 5 Effects of TSG-6 knockdown in hAT-MSCS on caerulein and LPS co-induced SAP. a Representative H\&E and TUNEL staining images of the pancreatic tissue sections in each group at 200x magnification. TUNEL staining revealed the number of cells undergoing apoptosis or pyroptosis. b The histological scores of H\&E and pancreas/body weight ratio were evaluated. c TUNEL-positive cells were counted for each group at 200x magnification. d Collected serum samples were analysed by ELISA for the evaluation of amylase activity, lipase activity, and TNF-a concentration. Results are presented as the mean $\pm S D .{ }^{*} P<0.05,{ }^{* *} P<0.01$ ( $n=5-8$ mice per group). MSC mesenchymal stem cells, PBS phosphate-buffered saline, SAP severe acute pancreatitis, scr scrambled, TSG-6 tumour necrosis factor-a-induced gene/protein 6 

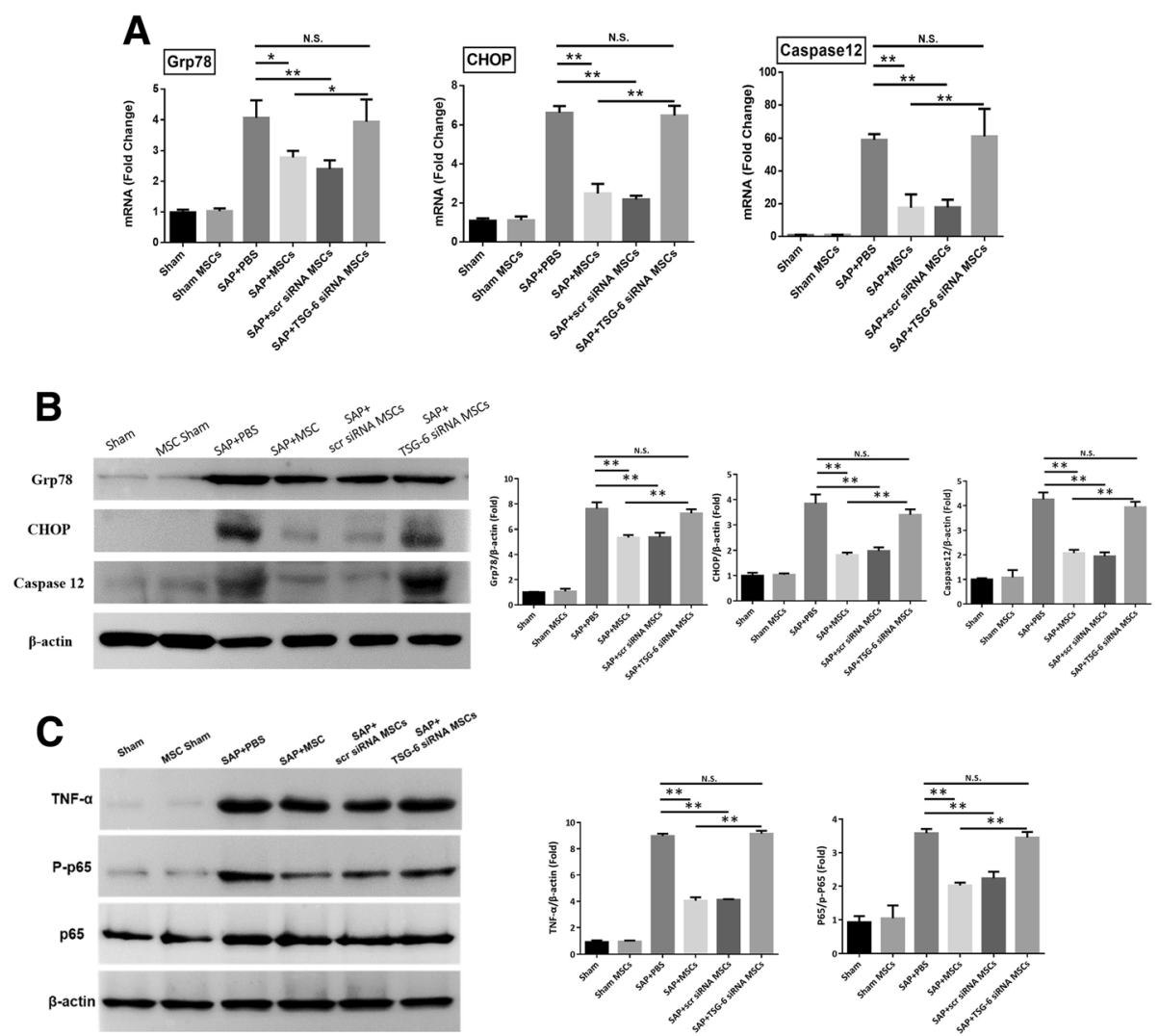

Fig. 6 Beneficial effects of hAT-MSCs depend on TSG-6 secretion due to ER stress and NF-KB activity. $\mathbf{a}, \mathbf{b}$ The mRNA and protein expression levels of Grp78, CHOP, and caspase-12 were analysed by qRT-PCR and western blotting, respectively. The band intensity on films is presented as the relative ratio of Grp78, CHOP, and caspase-12 to the band intensity of $\beta$-actin. c The expression levels of TNF-a and activity of p65 were analysed by western blotting. The band intensity on films is presented as the relative ratio of the level of TNF- $\alpha$ to that of $\beta$-actin; for NF-KB signalling, p65 activity was presented in the form of the ratio of phosphorylated p65 to p65. Results are presented as the mean \pm SD obtained from three independent experiments ${ }^{*} P<0.05,{ }^{* *} P<0.01$. CHOP CCAAT-enhancer-binding protein homologous protein, Grp7 78-kDa glucose-regulated protein, MSC mesenchymal stem cells, PBS phosphate-buffered saline, SAP severe acute pancreatitis, scr scrambled, TSG-6 tumour necrosis factor-a-induced gene/protein 6

groups treated with hAT-MSCs or hAT-MSCs transfected with scr siRNA showed a significant reduction in the expression levels of TNF- $\alpha$ and NF- $k B$ activity in the pancreatic tissues, while this effect was absent in groups treated with TSG-6 siRNA-transfected hAT-MSCs and PBS.

\section{Discussion}

Recent studies have shown the anti-inflammatory effects of hAT-MSCs on SAP; however, their mechanism of action is still unclear. In the present study, we found that the intraperitoneally administered hAT-MSCs ameliorated caerulein- and LPS-co-induced SAP in the absence of any significant engraftment of the hAT-MSCs. Our study also indicated that TSG-6, as the multifunctional protein with anti-inflammatory action, was secreted by hAT-MSCs in response to the inflammatory environment and ER stress. These results suggest that hAT-MSCs exert their effects on PACs via the downregulation of inflammatory response and ER stress during the early stages of SAP.

Several studies have demonstrated that SAP may be induced by various reagents. Mice treated with caerulein alone exhibited pancreatic inflammation, and hence, this model is suitable to study mild acute pancreatitis and is widely used for the analysis of intracellular changes during the early phase of acute pancreatitis [28]. The combination treatment with caerulein and LPS to induce SAP in mice results in easily to practice and the same pathological signs of human SAP, including pancreatic necrosis, oedema, and inflammation [24, 29]. To study the therapeutic effects of hAT-MSCs, caerulein- and LPS-induced SAP mice were evaluated 12, 24, and $48 \mathrm{~h}$ after hAT-MSC administration. The histopathological changes in pancreatitis scores significantly improved after one hAT-MSC treatment for 12, 24, and $48 \mathrm{~h}$; however, serum amylase and lipase activities were primarily detected at the $48 \mathrm{~h}$ time point. We concluded that 
hAT-MSCs are potentially capable of restricting SAP-induced pancreatic injury through the inhibition of PAC injury during the early stages. In addition, hAT-MSCs administration leads to the timely reduction in pancreatic damage and pancreatitis-associated lung injury. Thun, hAT-MSCs offer protection against the development of pancreatitis and systemic inflammation, which may cause the perpetuation of a vicious cycle.

PACs are rich in ER, which performs the function of synthesising digestive enzymes. These cells are more prone to damage caused by external stimuli, thus leading to ER stress [30]. During the early stages of pancreatitis, the ER structure undergoes significant changes, including swelling and vacuolisation [31,32]. Under normal conditions, ER stress sensors (inositol-requiring enzyme [IRE]-1 $\alpha$, protein kinase RNA [PKR]-like ER kinase [PERK], and activating transcription factor [ATF6]) are maintained in their inactive states through binding to the ER chaperone BiP (also known as Grp78). Both CHOP and caspase-12 are known as key factors that contribute to ER stress-induced apoptosis [11, 33, 34]. ER stress damages the acinar cell functions and induces apoptosis and inflammation response via ER stress and NF-kB signalling pathways [35-37]. In the present study, we evaluated whether the administered hAT-MSCs simultaneously regulate the inflammatory response and ER stress. As shown in Fig. 2, the levels of inflammatory cytokines (TNF- $\alpha$, IL-1 $\beta$, and IL-6) and ER stress-related markers (Grp78, CHOP, and caspase-12) were increased after caerulein and LPS stimulation in the pancreatic tissue at the $48 \mathrm{~h}$ time point, and hAT-MSC administration significantly reduced the levels of inflammatory cytokines and ER stress-related markers.

It is interesting to study the fate of MSCs after their intraperitoneal injection. It was demonstrated that intraperitoneally injected stem cells quickly form clusters with the resident innate immune cells in the peritoneal cavity and the resulting aggregation probably limits the access of stem cells into the systemic circulation [38]. We studied the distribution of intraperitoneally injected hAT-MSCs by qRT-PCR. After $2 \mathrm{~h}$ of the hAT-MSC administration, less than $1 \%$ of the total injected cells were detected in the heart, liver, lung, kidney, spleen, brain, and pancreas of SAP mice. Furthermore, we failed to detect hAT-MSCs in the pancreas after $12 \mathrm{~h}$, while the number of hAT-MSCs in other tissues was negligible after $48 \mathrm{~h}$.

Stem cells regulate the inflammatory response via the secretion of several molecules, including TGF- $\beta$, indoleamine-2,3-dioxygenase, and prostaglandin E2 (PGE2) [39, 40]. In addition, the therapeutic effects of MSCs were shown to be related to the expression level of TSG-6 [16, 20, 41-43]. Our recent study indicated that the upregulation of TSG- 6 expression in
TNF- $\alpha$-pre-conditioned hAT-MSCs significantly improved the therapeutic effects in IBD models [44]. Based on these results and our previous study, it is tempting to speculate if TSG-6 plays a critical role in SAP.

In this study, we constructed hAT-MSCs negative for TSG-6 expression to evaluate the levels of ER stress markers in PACs. The indirect co-culture of caeruleinand LPS-stimulated primary PACs and naive or siRNAtransfected hAT-MSCs in a transwell system showed that the levels of ER stress-related markers significantly increased in the positive control group and the group treated with TSG-6 siRNA-transfected hAT-MSCs, compared to the case in the groups treated with naive hAT-MSCs and scr siRNA-transfected hAT-MSCs. We measured the ratio of ER stress-induced apoptotic cells in vitro and found that the ratio decreased after the treatment with naive hAT-MSCs or hAT-MSCs transduced with scr siRNA; we failed to observe similar effects after treatment with TSG-6 siRNA-transfected hAT-MSCs. Our data suggest that TSG-6 plays a critical role in the alteration of the expression of ER stress-related markers and apoptotic ratio in PACs via a distant, indirect action.

Based on the aforementioned results, we evaluated the effects of TSG-6 released from hAT-MSCs in vivo. In comparison with SAP mice treated with PBS, those treated with TSG-6 siRNA-transfected hAT-MSCs showed no significant improvement in the histopathological score, and no significant reduction in the apoptotic ratio was observed. Serum amylase and lipase activities serve as clinical markers of acute pancreatitis and reveal the absence of any injury [45]. No significant reduction in these enzyme activities was observed in mice treated with TSG-6 siRNA-transfected hAT-MSCs. TNF- $\alpha$ is the most elevated cytokine, which plays a central role in SAP and mediates the early phase of inflammation and ER stress-related molecular activation [46]. The expression levels of TNF- $\alpha$ in serum and pancreatic tissue were measured by ELISA and western blotting, respectively. The administration of hAT-MSCs significantly reduced the expression levels of TNF- $\alpha$ in the serum and pancreatic tissue, while no change in the expression levels was observed after treatment with TSG-6 siRNA-transfected hAT-MSCs. Collectively, these results indicate that TSG-6 from hAT-MSCs inhibits the systemic and local TNF- $\alpha$ expression.

The NF- $\mathrm{kB}$ signalling pathway in PACs plays a vital and initial role in the induction of inflammatory cytokine expression [47] and ER stress-induced apoptosis [48-50]. Furthermore, NF- $\mathrm{kB}$ acts as an important link between ER stress and inflammatory response [51, 52]. The previous study has been revealed that therapeutic effects of TSG-6 were depended on CD44 expression by PACs and significantly inhibition NF- $\mathrm{kB}$ activation [41]. In the present study, we analysed the ratio of phosphorylated p65 to p65, 
and found a significant reduction in this ratio in the groups treated with naive hAT-MSCs and scr siRNAtransfected hAT-MSCs. This effect was absent in both the pancreatic tissue and PACs in the groups treated with TSG-6 siRNA-transfected hAT-MSCs.

There are some limitations in this study. Recent studies have showed adult stem cells from different donors varied widely in their efficacy, and the ability maybe influenced by various factors, including age and physiological status [53, 54]. Therefore, further studies using hAT-MSCs from different donors might help predict efficacy of stem cell therapy in pancreatitis patients. Also, it is possible that one or more factors from hAT-MSCs may contribute to the suppression of ER stress-induced apoptosis. Hepatocyte growth factor secreted by bone marrow-derived mesenchymal stem cells was shown to reduce ER stress in alveolar epithelial cells [55]. Further studies are warranted to investigate if NF-kB inhibitors affect the ER stress pathway after hAT-MSC administration. Above all, TSG-6 plays an important role in ER stress-induced apoptosis and early phase of inflammatory response, probably by reducing the ER stress and inhibiting the NF- $\mathrm{KB}$ pathway in PACs.

\section{Conclusions}

In summary, we showed that intraperitoneally administered hAT-MSCs significantly alleviated inflammation from pancreatic injury in an SAP mouse model. The beneficial effects of hAT-MSCs were demonstrated with the absence of any significant engraftment of hAT-MSCs in the injured pancreatic tissue. These effects were dependent on TSG-6, a critical anti-inflammatory cytokine secreted after TNF- $\alpha$ stimulation. Furthermore, TSG-6 secreted from hAT-MSCs significantly suppressed ER stress-induced apoptosis and NF- $\mathrm{kB}$ activity in PACs during the early stage of SAP. These findings may facilitate the development of MSCbased therapeutic strategies for the treatment of SAP.

\section{Additional files}

Additional file 1: Methods. Characterisation of human adipose tissuederived mesenchymal stem cells; characterisation of pancreatic acinar cells; cell viability assay. (DOCX $21 \mathrm{~kb}$ )

Additional file 2: Figure S1. Characterisation of human adipose tissuederived mesenchymal stem cells. (JPG $349 \mathrm{~kb})$

Additional file 3: Figure S2. Characterisation of mouse primary pancreatic acinar cells and caerulein plus LPS stimulation assay. (JPG $242 \mathrm{~kb}$ )

Additional file 4: Table S1. Histopathological scoring of pancreatic injury; Table S2. Primers used for this study. (DOCX 27 kb)

Additional file 5: Figure S3. Effects of hAT-MSCs on severe acute pancreatitis (SAP)-associated lung injury in mice. (JPG $454 \mathrm{~kb}$ )

\section{Abbreviations}

ATF: Activating transcription factor; CHOP: CCAAT-enhancer-binding protein homologous protein; DMEM: Dulbecco's modified Eagle's medium; ELISA: Enzyme-linked immunosorbent assay; ER: Endoplasmic reticulum; FBS: Foetal bovine serum; GAPDH: Glyceraldehyde-3-phosphate dehydrogenase; Grp78: 78-kDa glucose-regulated protein; H\&E: Haematoxylin and eosin; hATMSCs: Human adipose tissue-derived mesenchymal stem cells; IBD: Inflammatory bowel disease; IL: Interleukin; IRB: Institutional Review Board; IRE: Inositolrequiring enzyme; LPS: Lipopolysaccharide; NF-kB: Nuclear factor kappa B; MSCs: Mesenchymal stem cells; PACs: Pancreatic acinar cells; PBS: Phosphate-buffered saline; PERK: Protein kinase RNA [PKR]-like ER kinase; PGE2: Prostaglandin E2; qRT-PCR: Quantitative reverse transcription polymerase chain reaction; SAP: Severe acute pancreatitis; scr: Scrambled; TNF-a: Tumour necrosis factor alpha; TSG-6: Tumour necrosis factor-ainduced gene/protein 6

\section{Acknowledgements}

This study was supported by the Research Institute for Veterinary Science and BK21 PLUS Program for Creative Veterinary Science Research. Also, hATMSCs used in this study were kindly provided by Dr. Sung-Keun Kang, Biostar Stem Cell Research Institute, R Bio Co. Ltd., Seoul.

\section{Funding}

This study was supported by the Research Institute for Veterinary Science and the BK21 PLUS Program for Creative Veterinary Science Research.

\section{Availability of data and materials}

The datasets used and/or analysed during the current study are available from the corresponding author on reasonable request.

\section{Authors' contributions}

QL contributed to conception and design, collection and/or assembly of data, data analysis and interpretation, and manuscript writing. W-JS contributed to conception and design, collection and/or assembly of data, manuscript writing. $\mathrm{M}-\mathrm{OR}$ and AN contributed to provision of study material or patients, collection and/or assembly of data. J-HA contributed to collection and/or assembly of data, data analysis and interpretation. J-OA contributed to provision of study material or patients, collection and/or assembly of data, data analysis and interpretation. DHB and YCJ contributed to administrative support, and provision of study material or patients. $\mathrm{H}-\mathrm{YY}$ contributed to conception and design, data analysis and interpretation, and final approval of manuscript. All authors read and approved the final manuscript.

\section{Ethics approval and consent to participate}

Adipose tissue from a donor after receiving written informed consent and according to guidelines of the Institutional Review Board (IRB) of the R bio (IRB No. RBIO-2016-04-001).

\section{Consent for publication}

Not applicable.

\section{Competing interests}

The authors declare that they have no competing interests.

\section{Publisher's Note}

Springer Nature remains neutral with regard to jurisdictional claims in published maps and institutional affiliations.

\section{Author details}

${ }^{1}$ Laboratory of Veterinary Internal Medicine, College of Veterinary Medicine, Seoul National University, 1 Gwanak-ro, Gwanak-gu, Seoul 08826, Republic of Korea. ${ }^{2}$ Department of Molecular and Cellular Biology, Samsung Biomedical Research Institute, Sungkyunkwan University School of Medicine, Suwon, Gyeonggi-do 16419, Republic of Korea. ${ }^{3}$ BK21Plus program for 21st Century Biomedical Science Leader Development, Sungkyunkwan University School of Medicine, Suwon, Gyeonggi-do 16419, Republic of Korea. ${ }^{4}$ Chaon, A-301-3, 240, Pangyoyeok-ro, Bundang-gu, Seongnam-si, Gyeonggi-do 13488, Republic of Korea. 
Received: 3 August 2018 Revised: 4 September 2018 Accepted: 14 September 2018 Published online: 26 September 2018

\section{References}

1. Jakkampudi A, Jangala R, Reddy BR, Mitnala S, Reddy DN, Talukdar R. NF-kB in acute pancreatitis: Mechanisms and therapeutic potential. Pancreatology. 2016;16(4):477-88.

2. Brock $C$, Nielsen LM, Lelic D, Drewes AM. Pathophysiology of chronic pancreatitis. World J Gastroentero. 2013;19(42):7231.

3. Xiao W, Jiang W, Li K, Hu Y, Li S, Zhou L, et al. Protective effect of asiatic acid in an experimental cerulein-induced model of acute pancreatitis in mice. Am J Transl Res. 2017;9(8):3842.

4. Jakkampudi A, Jangala R, Reddy R, Mitnala S, Rao GV, Pradeep R, et al. Acinar injury and early cytokine response in human acute biliary pancreatitis. Sci Rep. 2017;7(1):15276.

5. Cnop M, Foufelle F, Velloso LA. Endoplasmic reticulum stress, obesity and diabetes. Trends Mol Med. 2012;18(1):59-68.

6. He Y, Zhang D, Zeng Y, Ma J, Wang J, Guo H, et al. Bone marrow-derived mesenchymal stem cells protect islet grafts against endoplasmic reticulum stress-induced apoptosis during the early stage after transplantation. Stem Cells. 2018;36(7):1045-61.

7. Chen Y, Zhang J, Zhao Q, Chen Q, Sun Y, Jin Y, et al. Melatonin induces antiinflammatory effects to play a protective role via endoplasmic reticulum stress in acute pancreatitis. Cell Physiol Biochem. 2016;40(5):1094-104.

8. Kim S, Joe Y, Kim HJ, Kim Y-S, Jeong SO, Pae H-O, et al. Endoplasmic reticulum stress-induced IRE 1a activation mediates cross-talk of GSK-3 $\beta$ and XBP-1 To regulate inflammatory cytokine production. J Immunol. 2015; 194(9):4498-506.

9. Xue X, Piao J-H, Nakajima A, Sakon-Komazawa S, Kojima Y, Mori K, et al. Tumor necrosis factor a (TNFa) induces the unfolded protein response (UPR) in a reactive oxygen species (ROS)-dependent fashion, and the UPR counteracts ROS accumulation by TNFa. J Biol Chem. 2005;280(40):33917-25.

10. Wu JS, Li WM, Chen YN, Zhao Q, Chen QF. Endoplasmic reticulum stress is activated in acute pancreatitis. J Digest Dis. 2016;17:295-303.

11. Zhang K, Kaufman RJ. From endoplasmic-reticulum stress to the inflammatory response. Nature. 2008;454(7203):455.

12. Gonzalez-Rey E, Gonzalez MA, Rico L, Buscher D, Delgado M. Human adult stem cells derived from adipose tissue protect against experimental colitis and sepsis. Gut. 2009;58(7):929-39.

13. Jung KH, Song SU, Yi T, Jeon MS, Hong SW, Zheng HM, et al. Human bone marrow-derived clonal mesenchymal stem cells inhibit inflammation and reduce acute pancreatitis in rats. Gastroenterology. 2011;140(3):998-1008. e4.

14. Prockop DJ, Oh JY. Mesenchymal stem/stromal cells (MSCs): role as guardians of inflammation. Mol Ther. 2012;20(1):14-20.

15. Wu H, Mahato RI. Mesenchymal stem cell-based therapy for type 1 diabetes. Discov Med. 2014;17(93):139-43.

16. Choi H, Lee RH, Bazhanov N, Oh JY, Prockop DJ. Anti-inflammatory protein TSG-6 secreted by activated MSCs attenuates zymosan-induced mouse peritonitis by decreasing TLR2/NF-KB signaling in resident macrophages. Blood. 2011;118(2):330-8.

17. Lee RH, Pulin AA, Seo MJ, Kota DJ, Ylostalo J, Larson BL, et al. Intravenous hMSCs improve myocardial infarction in mice because cells embolized in lung are activated to secrete the anti-inflammatory protein TSG-6. Cell Stem Cell. 2009:5(1):54-63.

18. Sala E, Genua M, Petti L, Anselmo A, Arena V, Cibella J, et al. Mesenchymal stem cells reduce colitis in mice via release of TSG6, independently of their localization to the intestine. Gastroenterology. 2015;149(1):163-76. e20.

19. Qi Y, Jiang D, Sindrilaru A, Stegemann A, Schatz S, Treiber N, et al. TSG-6 released from intradermally injected mesenchymal stem cells accelerates wound healing and reduces tissue fibrosis in murine full-thickness skin wounds. J Invest Dermatol. 2014;134(2):526-37.

20. Danchuk S, Ylostalo JH, Hossain F, Sorge R, Ramsey A, Bonvillain RW, et al. Human multipotent stromal cells attenuate lipopolysaccharide-induced acute lung injury in mice via secretion of tumor necrosis factor-a-induced protein 6. Stem Cell Res Ther. 2011;2(3):27.

21. Gout J, Pommier RM, Vincent DF, Kaniewski B, Martel S, Valcourt U, et al. Isolation and culture of mouse primary pancreatic acinar cells. Jove-J Vis Exp. 2013;(78):e50514.

22. Williams JA. Isolation of rodent pancreatic acinar cells and acini by collagenase digestion Pancreapedia: Exocrine Pancreas Knowledge Base; 2010. https://doi.org/10.3998/panc.2010.18 Available from: https://www. pancreapedia.org/tools/methods/isolation-of-rodent-pancreatic-acinar-cellsandacini-by-collagenase-digestion. Accessed 30 Mar 2018.

23. Singh L, Bakshi DK, Vasishta RK, Arora SK, Majumdar S, Wig JD. Primary culture of pancreatic (human) acinar cells. Dig Dis Sci. 2008;53(9):2569-75.

24. Ding S-P, Li J-C, Jin C. A mouse model of severe acute pancreatitis induced with caerulein and lipopolysaccharide. World J Gastroentero. 2003;9(3):584

25. Schmidt J, Rattner DW, Lewandrowski K, Compton CC, Mandavilli U, Knoefel WT, et al. A better model of acute pancreatitis for evaluating therapy. Ann Surg. 1992;215(1):44

26. Pan Y, Li Y, Gao L, Tong Z, Ye B, Liu S, et al. Development of a novel model of hypertriglyceridemic acute pancreatitis in mice. Sci Rep. 2017;7:40799.

27. Song W-J, Li Q, Ryu M-O, Ahn J-O, Bhang DH, Jung YC, et al. TSG-6 Secreted by human adipose tissue-derived mesenchymal stem cells ameliorates DSS-induced colitis by inducing M2 macrophage polarization in mice. Sci Rep. 2017;7(1):5187.

28. Hyun JJ, Lee HS. Experimental models of pancreatitis. Clin Endosc. 2014; 47(3):212.

29. Chao K, Chao K, Chuang C, Liu S. Blockade of interleukin 6 accelerates acinar cell apoptosis and attenuates experimental acute pancreatitis in vivo. Brit J Surg. 2006;93(3):332-8.

30. Kubisch $\mathrm{CH}$, Logsdon CD. Endoplasmic reticulum stress and the pancreatic acinar cell. Expert Rev Gastroent. 2008;2(2):249-60.

31. Deng W-H, Chen C, Wang W-X, Yu J, Li J-Y, Liu L. Effects of ORP150 on appearance and function of pancreatic beta cells following acute necrotizing pancreatitis. Pathol Res Pract. 2011;207(6):370-6.

32. Hartley T, Siva M, Lai E, Teodoro T, Zhang L, Volchuk A. Endoplasmic reticulum stress response in an INS-1 pancreatic $\beta$-cell line with inducible expression of a folding-deficient proinsulin. BMC Cell Biol. 2010;11(1):59.

33. Nishitoh H. CHOP is a multifunctional transcription factor in the ER stress response. J Biochem. 2012;151(3):217-9.

34. Nakagawa T, Zhu H, Morishima N, Li E, Xu J, Yankner BA, et al. Caspase-12 mediates endoplasmic-reticulum-specific apoptosis and cytotoxicity by amyloid- $\beta$. Nature. 2000;403(6765):98.

35. Sah RP, Dawra RK, Saluja AK. New insights into the pathogenesis of pancreatitis. Curr Opin Gastroen. 2013;29(5):523.

36. Hitomi J, Katayama T, Taniguchi M, Honda A, Imaizumi K, Tohyama M. Apoptosis induced by endoplasmic reticulum stress depends on activation of caspase-3 via caspase-12. Neurosci Lett. 2004;357(2):127-30.

37. Zhu X, Huang L, Gong J, Shi C, Wang Z, Ye B, et al. NF-kB pathway link with ER stress-induced autophagy and apoptosis in cervical tumor cells. Cell death Discov. 2017:3:17059.

38. Bazhanov N, Ylostalo JH, Bartosh TJ, Tiblow A, Mohammadipoor A, Foskett A, et al. Intraperitoneally infused human mesenchymal stem cells form aggregates with mouse immune cells and attach to peritoneal organs. Stem Cell Res Ther. 2016;7(1):27.

39. Kim HS, Yun JW, Shin TH, Lee SH, Lee BC, Yu KR, et al. Human umbilical cord blood mesenchymal stem cell-derived PGE2 and TGF- $\beta 1$ alleviate atopic dermatitis by reducing mast cell degranulation. Stem Cells. 2015;33(4):1254-66.

40. Gonzalo-Gil E, Pérez-Lorenzo MJ, Galindo M, de la Guardia RD, López-Millán B, Bueno C, et al. Human embryonic stem cell-derived mesenchymal stromal cells ameliorate collagen-induced arthritis by inducing host-derived indoleamine 2, 3 dioxygenase. Arthritis Res Ther. 2016;18(1):77.

41. He Z, Hua J, Qian D, Gong J, Lin S, Xu C, et al. Intravenous hMSCs ameliorate acute pancreatitis in mice via secretion of tumor necrosis factora stimulated gene/protein 6. Sci Rep. 2016;6:38438.

42. Wang $\mathrm{N}, \mathrm{Li} \mathrm{Q}$, Zhang L, Lin H, Hu J, Li D, et al. Mesenchymal stem cells attenuate peritoneal injury through secretion of TSG-6. PLoS One. 2012;7(8):e43768.

43. Liu L, Song H, Duan H, Chai J, Yang J, Li X, et al. TSG-6 secreted by human umbilical cord-MSCs attenuates severe burn-induced excessive inflammation via inhibiting activations of P38 and JNK signaling. Sci Rep. 2016;6:30121.

44. Song W-J, Li Q, Ryu M-O, Ahn J-O, Bhang DH, Jung YC, et al. TSG-6 released from intraperitoneally injected canine adipose tissue-derived mesenchymal stem cells ameliorate inflammatory bowel disease by inducing M2 macrophage switch in mice. Stem Cell Res Ther. 2018;9(1):91.

45. Adler G, Rohr G, Kern HF. Alteration of membrane fusion as a cause of acute pancreatitis in the rat. Digest Dis Sci. 1982;27(11):993-1002.

46. Surbatovic M, Radakovic S. Tumor necrosis factor-a levels early in severe acute pancreatitis: is there predictive value regarding severity and outcome? J Clin Gastroenterol. 2013:47(7):637-43.

47. Huang H, Liu Y, Daniluk J, Gaiser S, Chu J, Wang H, et al. Activation of nuclear factor- $\mathrm{KB}$ in acinar cells increases the severity of pancreatitis in mice. Gastroenterology. 2013;144(1):202-10. 
48. Qian D, Wei G, Xu C, He Z, Hua J, Li J, et al. Bone marrow-derived mesenchymal stem cells (BMSCs) repair acute necrotized pancreatitis by secreting microRNA-9 to target the NF-kB1/p50 gene in rats. Sci Rep. 2017:7(1):581.

49. Pahl HL, Baeuerle PA. The ER-overload response: activation of NF-KB. Trends Biochem Sci. 1997;22(2):63-7.

50. Paul M, Kemparaju K, Girish KS. Inhibition of constitutive NF-KB activity induces platelet apoptosis via ER stress. Biochem Bioph Res CO. 2017;493(4): $1471-7$.

51. Baker RG, Hayden MS, Ghosh S. NF-KB, inflammation, and metabolic disease. Cell Metab. 2011;13(1):11-22.

52. Cao SS, Luo KL, Shi L. Endoplasmic reticulum stress interacts with inflammation in human diseases. J Cell Physiol. 2016;231(2):288-94.

53. Mohamed-Ahmed S, Fristad I, Lie SA, Suliman S, Mustafa K, Vindenes H, Idris SB. Adipose-derived and bone marrow mesenchymal stem cells: a donormatched comparison. Stem Cell Res Ther. 2018;9(1):168.

54. Siddappa $R$, Licht $R$, van Blitterswijk C, de Boer J. Donor variation and loss of multipotency during in vitro expansion of human mesenchymal stem cells for bone tissue engineering. J Orthop Res. 2007;25(8):1029-41.

55. Nita I, Hostettler K, Tamo L, Medová M, Bombaci G, Zhong J, et al.

Hepatocyte growth factor secreted by bone marrow stem cell reduce ER stress and improves repair in alveolar epithelial II cells. Sci Rep. 2017:7:41901.

Ready to submit your research? Choose BMC and benefit from:

- fast, convenient online submission

- thorough peer review by experienced researchers in your field

- rapid publication on acceptance

- support for research data, including large and complex data types

- gold Open Access which fosters wider collaboration and increased citations

- maximum visibility for your research: over $100 \mathrm{M}$ website views per year

At $\mathrm{BMC}$, research is always in progress.

Learn more biomedcentral.com/submissions 